\title{
Perforated Jejunal Adenocarcinoma in a COVID-19-Positive Patient*
}

\section{Adenocarcinoma jejunal perfurado em paciente positivo para covid-19}

\author{
Jorge Said Haro Cruz ${ }^{10}$ Ana Cristina Díaz Degollado ${ }^{10}$ Ricardo García Iturbide ${ }^{10}$ \\ Claudio Daniel Rojas Gutiérrez ${ }^{10}$ Javier Alba Macías ${ }^{10}$ Andrei Coria Hernández ${ }^{1,2}$
}

${ }^{1}$ Department of General Surgery, Hospital General de Zona 1A, Instituto Mexicano del Seguro Social, Ciudad de México, México

2 Department of General Surgery, Hospital Ángeles México, Ciudad de México, México

\begin{abstract}
Address for correspondence Jorge Said Haro Cruz, First-Year General Surgery Resident, Avenida Municipio Libre \#270, Colonia Portales Norte, Delegación Benito Juárez, Ciudad de México, 03300, México (e-mail: jorgeharocruz@gmail.com).
\end{abstract}

J Coloproctol 2021;41(2):210-214.

\begin{abstract}
Keywords

- adenocarcinoma

- COVID-19

- intestinal perforation

- jejunal neoplasms

\section{Resumo}

\section{Palavras-chave}

- adenocarcinoma

- covid-19

- neoplasias jejunais

- perfuração intestinal

Jejunal adenocarcinoma is a rare type of primary small bowel malignancy. It is generally diagnosed at late stages and as a surgical finding, with abdominal pain or discomfort being the main associated symptom. Cases presenting with perforation are even rarer, especially without disseminated disease. The relationship between cancer and coronavirus disease 2019 (COVID-19) is still being studied, as well as the postsurgical evolution of COVID-19 patients and its possible causality of intestinal perforation. We present the case of a perforated jejunal adenocarcinoma in a COVID-19-positive patient, in whom the symptomatology secondary to the perforation led to an early diagnosis, treatment and adequate postsurgical evolution, despite the concomitant condition.

O adenocarcinoma jejunal é um tipo raro de malignidade primária do intestino delgado, o qual geralmente é diagnosticado em estágios tardios e como achado cirúrgico, sendo a dor ou o desconforto abdominal o principal sintoma associado. Casos que apresentam perfuração são ainda mais raros, principalmente sem doença disseminada. A relação entre câncer e a cornonavirus disease 2019 (covid-19) ainda está sendo estudada, assim como a evolução pós-cirúrgica de pacientes com covid-19 e sua possível causalidade de perfuração intestinal. Apresentamos o caso de um adenocarcinoma jejunal perfurado em um paciente positivo para covid-19, em que a sintomatologia secundária à perfuração levou a um diagnóstico precoce, tratamento e evolução pós-cirúrgica adequada, apesar da condição concomitante.
\end{abstract}

Study conducted at Hospital General de Zona 1A, Department of Surgery, Instituto Mexicano del Seguro Social, Ciudad de México, México. received

July 16,2020

accepted

September 2, 2020

published online

May 24, 2021
DOI https://doi.org/

10.1055/s-0041-1724069.

ISSN 2237-9363. (c) 2021. Sociedade Brasileira de Coloproctologia. All rights reserved.

This is an open access article published by Thieme under the terms of the Creative Commons Attribution-NonDerivative-NonCommercial-License, permitting copying and reproduction so long as the original work is given appropriate credit. Contents may not be used for commercial purposes, or adapted, remixed, transformed or built upon. (https://creativecommons.org/ licenses/by-nc-nd/4.0/)

Thieme Revinter Publicações Ltda., Rua do Matoso 170, Rio de Janeiro, RJ, CEP 20270-135, Brazil 


\section{Introduction}

Jejunal adenocarcinoma constitutes an infrequent subtype of small bowel adenocarcinoma, an already rare type of cancer that accounts for $3 \%$ of all gastrointestinal malignancies and that presents with an estimated 11,000 new cases annually in the United States. ${ }^{1,2}$ The clinical presentation is usually unspecific, with the main reported symptom being an intermittent, cramping abdominal pain in up to $71.7 \%$ of patients, which is particularly present in distal lesions. Most cases are detected in advanced stages as a result of a delay in diagnosis due to the uncharacteristic symptomatology and to the anatomic location of the disease. Management strategies remain controversial, with a surgical approach being the first line of treatment, and the benefit of chemotherapeutic agents remains unclear. ${ }^{3}$

The coronavirus disease 2019 (COVID-19) is an infectious disease caused by severe acute respiratory syndrome coronavirus 2 . Throughout the year of 2020, it has become a global health issue, with an estimated 12,964,809 cases and 570,288 deaths reported to the World Health Organization (WHO) by mid-July. ${ }^{4}$ Although it was initially mainly associated with respiratory symptoms, organic affection became more noticeable as the amount of cases increased exponentially, with gastrointestinal and thrombotic manifestations shown to be present in a significant percentage of patients. ${ }^{5}$

The authors present the case of a patient with a perforated jejunal adenocarcinoma, who was found to be COVID-19positive, which may have influenced such a rare presentation.

\section{Case Report}

A 71-year-old female patient arrived at our unit after 6 days of constipation, accompanied by abdominal pain. On the $3^{\text {rd }}$ day of her clinical course, she presented with a complete intestinal obstruction. She had previous history of systemic arterial hypertension, depression, and gastrointestinal bleeding as well as a 10-year history of intermittent abdominal pain. Her only previous surgeries included a cesarean section and cervical and lumbar laminectomies.

The patient was checked into our hospital for conservative management of her intestinal obstruction with intestinal decompression and fluid therapy. X-rays and laboratory studies were ordered, showing hydro-air levels in the small bowel, free abdominal fluid, and leukocytosis (33,000 per $\mathrm{mm} 3$ ) with neutrophilia (90.2\%). The rest of her blood tests showed no significant abnormalities.

On physical examination, she presented with diffuse abdominal pain, reduced peristalsis, positive Blumberg sign and an increase in muscle resistance along the midline, particularly at the mesogastric level. No respiratory symptoms were present, and she had proper saturation levels without oxygen support.

The patient underwent an exploratory laparotomy due to suspicion of abdominal sepsis secondary to a strangulated small bowel loop. The procedure evidenced a purulent, fibrinous material covering multiple small bowel loops, thus causing them to adhere to each other, as well as a punctate

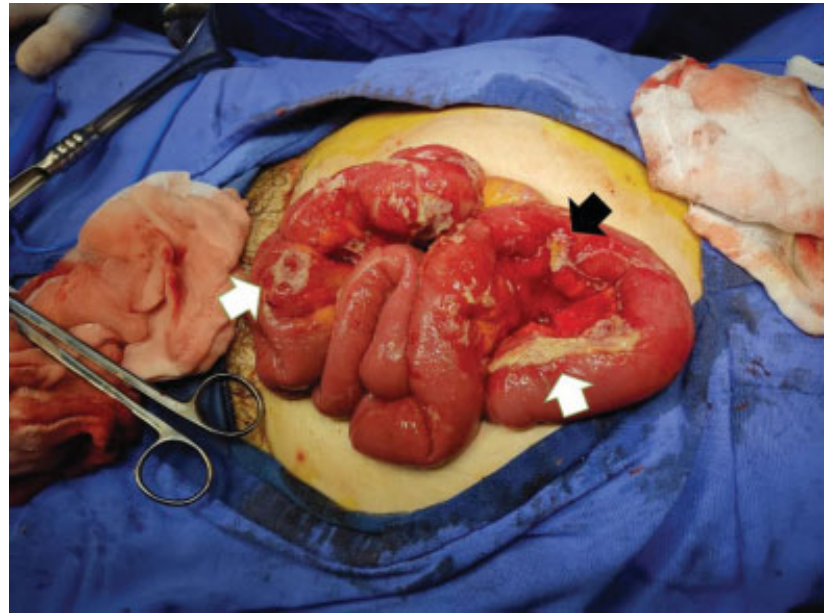

Fig. 1 Trans surgical findings. Fibrinopurulent plaques adhered to small bowel loops (white arrows) after the initial adhesions had been excised. A punctiform perforation can be observed (black arrow), with intestinal material leakage.

lesion in the jejunum with low output leakage of intestinal content. A 51-centimeter jejunal segment was resected and an intestinal end-to-end hand-sewn anastomosis was performed (-Fig. 1).

On her first postoperative day, a central venous catheter was placed, and parenteral nutrition was initiated. The patient continued with an appropriate postsurgical evolution until the $3^{\text {rd }}$ postoperative day, when she developed a dry cough and began exhibiting lower oxygen saturation levels. Chest $\mathrm{x}$-rays were taken on alternate days due to COVID-19 suspicion, and a reverse transcription-polymerase chain reaction (RT-PCR) test was ordered (-Fig. 2). She continued to show a favorable evolution, requiring only one to two liters of oxygen per minute to achieve adequate saturation levels, and initiating liquid enteral feeding on her $6^{\text {th }}$ postoperative day. The RT-PCR test showed a positive result for COVID-19 infection. The patient remained in the hospital for 2 more days, and then requested a voluntary discharge. She continued her recovery and isolation in her home, with telephonic check-ups confirming a satisfactory evolution 1 month after her surgery.

The anatomopathological report showed a $2.5 \times 2 \times 2$-centimeters lesion, identified as a moderately differentiated adenocarcinoma that ranged from the visceral peritoneum to the serosa, with negative surgical margins (stage T4NOMX) (-Fig. 3).

\section{Discussion}

Small bowel cancer is a rare phenomenon, even though the small intestine represents $\sim 75 \%$ of the length and over $90 \%$ of the surface area of the alimentary tract. In the United States, there are $\sim 11,110$ new cases and 1,700 patient deaths from small bowel cancer annually, representing $\sim 0.6 \%$ of their annual load of new cancer cases, and $<3 \%$ of all gastrointestinal malignancies. It has an approximate incidence of 2.4 per 100,000 inhabitants, an apparent predominance for black 


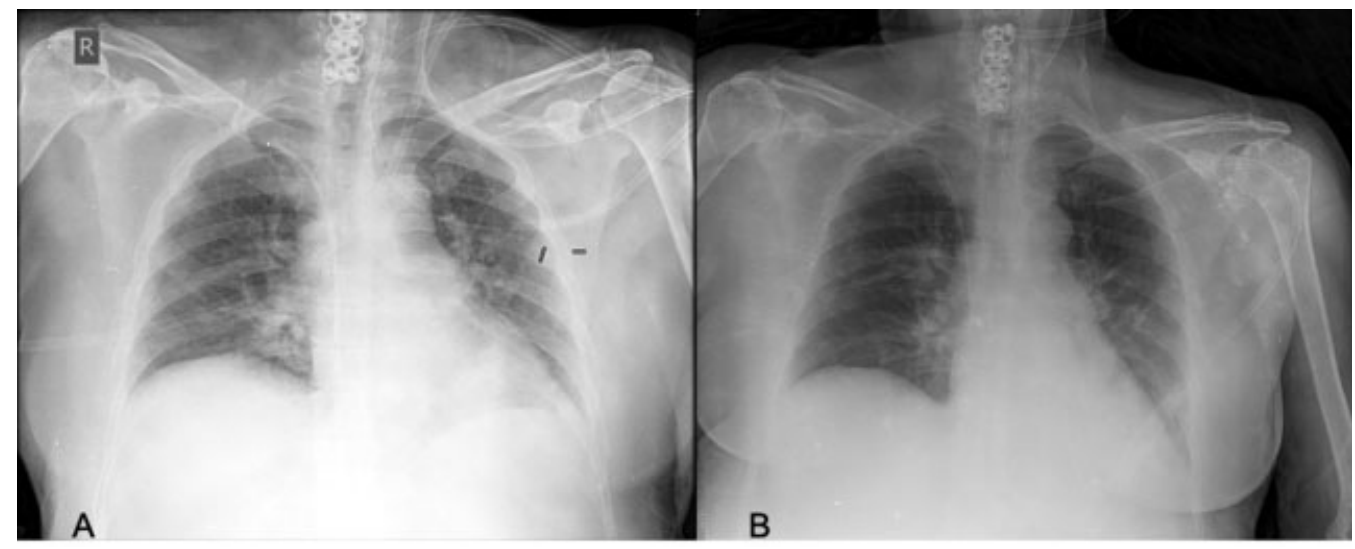

Fig. 2 Chest $x$-rays during the second and fourth postsurgical days. Chest $x$-rays taken during the second (A) and fourth (B) postsurgical days. The initial $\mathrm{x}$-ray was ordered to check for the correct placement of the central venous catheter. The second $\mathrm{x}$-ray was ordered to monitor the respiratory symptoms referred by the patient. Slight peripheral interstitial affection can be observed.

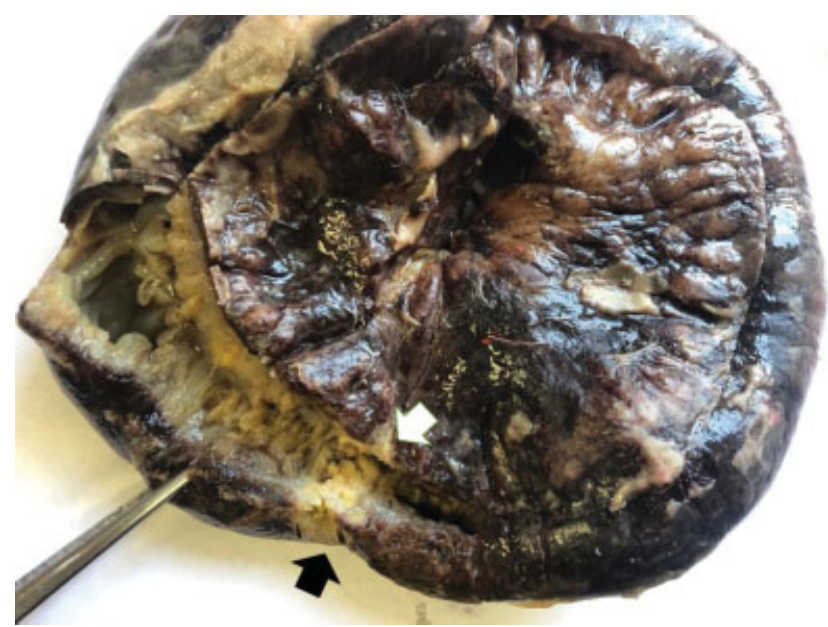

Fig. 3 Anatomopathological examination of the resected jejunum. A stricture can be observed at the site of the tumoral lesion (white arrow), with the perforation being evident in the antimesenteric border (black arrow).

males and a median age at diagnosis of between 55 and 66 years old. ${ }^{1,6}$ Of these types of tumors, only 13.2 to $31 \%$ of cases seem to affect the jejunum, with the duodenum acting as the main location in most patients (between 48 and $73.6 \%$ of cases). ${ }^{3}$

For a long time, adenocarcinomas were the most common histological type of malignant neoplasm affecting the small bowel, with up to $45 \%$ of cases; nevertheless, over the last 2 decades, neuroendocrine tumors have increased their incidence, becoming the main type of small bowel cancer in current times ( $44 \%$ versus $33 \%$ of cases). Adenocarcinomas are mainly found in the duodenum, with neuroendocrine tumors mainly affecting the ileum, and no particular histological subtype proclivity being currently described for the jejunum. ${ }^{7}$

The lower incidence associated with this pathology when compared with other gastrointestinal tract cancers is hypothesized to be secondary to the rapid transit of chymus through the small intestine, which allows for a shorter exposure to carcinogens and less irritation of the mucosa. Another theory exposes that a smaller bacterial load, when compared with the more distal portions of the alimentary tract, leads to less carcinogens forming from bile acid breakdown by the intestinal microbiota. ${ }^{8}$ Another hypothesis includes a larger amount of immunoglobulin-A due to the prevalence of intestinal lymphoid tissue, and the enormous self-renewing capacity of the intestinal epithelium, which is able to completely replace itself in 4 to 5 days. $^{9}$

Some modifiable and nonmodifiable risk factors for small intestine adenocarcinoma have been identified; of these, several have an obvious overlap with risk factors associated with colorectal cancer. Some of the modifiable risk factors are alcohol, smoking, refined carbohydrates, red meat, and smoked foods. Nonmodifiable risk factors include familial adenomatous polyposis, Lynch syndrome, Peutz-Jeghers syndrome, Crohn's disease, and both hereditary colorectal nonpolyposis as well as the antecedent of non-hereditary colorectal cancer. ${ }^{6,10}$

Another similarity with colorectal cancer is that most small intestine adenocarcinomas also seem to arise from adenomas through a sequence of specific genetic changes. Some of these changes include mutations in the p53 tumor suppressor gene and in the Kirsten rat sarcoma (KRAS) oncogene, which have been implicated in up to $50 \%$ of cases, as well as mutations in the adenomatous polyposis coli tumor suppressor gene, present in $\sim 10 \%$ of cases. ${ }^{11}$

The presenting clinical picture for these tumors is usually vague, particularly in its early stages, being either asymptomatic or having a predominance of nonspecific abdominal discomfort or pain, which may be accompanied by weight loss, anemia, vomiting, and nausea as the disease progresses, eventually leading to obstruction and/or perforation of the bowel. Due to this, the diagnosis is usually delayed and takes place during surgical intervention or at advanced stages of the disease, worsening the prognosis for the patient. ${ }^{8,10}$

Finding and locating tumors in the small intestine, particularly in the jejunum and in the ileum, is a current challenge. The barium series technique has a sensitivity of $\sim 60 \%$, while computed tomography $(\mathrm{CT})$ and magnetic resonance imaging (MRI) have reported different degrees of sensitivity according to tumor location and disease stage, ranging from 47 to $80 \%$. Standard endoscopic techniques are generally useless in jejunal 
adenocarcinoma, due to their limitation in exploring $<40 \%$ of the small bowel. The wireless endoscopic capsule allows for imaging of the entire length of the small intestine, but it does not allow the user to take biopsies of the imaged tissues. The accuracy has increased with the use of CT enterography/enteroclysis, achieving an approximate sensibility of 84.7 to $92.7 \%$ in different series. As previously mentioned, the operating room plays a key role in the diagnosis in up to $85 \%$ of cases. ${ }^{3,8,10,12}$ After the diagnosis, French guidelines recommend performing a thoraco-abdomino-pelvic tomographic scan to detect possible distant metastases, as well as both upper and lower endoscopy to look for other tumors that may suggest a predisposing genetic syndrome. Carcinoembryonic antigen (CEA) and carbohydrate antigen 19.9 (CA 19.9) should be measured at baseline, as these tumor markers may have a prognostic value, particularly in advanced disease. ${ }^{13}$

Due to its rare incidence, an adequate treatment strategy for jejunal adenocarcinoma remains controversial. Early, localized disease is best treated with a complete surgical resection (R0) of the primary tumor, as well as of locoregional lymph nodes. ${ }^{14}$ As previously mentioned, guidelines for a standardized approach are not currently available, but the literature recommends a wide resection, removing both the mesentery and lymphatics up to the superior mesenteric vessels, with a minimum of 12 lymph nodes obtained for pathologic evaluation. As previously mentioned, this recommendations stem mainly from current knowledge of the appropriate management of colorectal cancer. ${ }^{8,12}$ Surgical intervention is generally needed even in advanced stages, due to the high risk of obstruction or bleeding, which can usually be the first manifestation of an otherwise clinically silent or nonspecific presentation. ${ }^{1,9}$

The role of chemotherapy in the management of both localized and disseminated disease has been a matter of debate in recent years. No standard chemotherapy regimen exists to date, but adjuvant treatment for metastatic adenocarcinoma is usually carried out with 5-Fluorouracil as the sole agent, this choice being also extrapolated from the current management options for colon adenocarcinoma. ${ }^{12}$ Capecitabine and oxaliplatin (CAPOX), folinic acid/5-FU/oxaliplatin (FOLFOX), and folinic acid/5-FU/irinotecan (FOLFIRI) are promising therapeutic options, but more randomized clinical trials are needed to evaluate the efficacy of these treatment methods, as well as that of chemotherapy itself for this rare type of malignancy. ${ }^{10}$

The currently accepted staging system for small bowel adenocarcinomas is the tumor, node, metastasis (TNM) system of the combined American Joint Committee on Cancer/Union for International Cancer Control. Its most recent edition revised the definitions of the $\mathrm{T}$ stage, with $\mathrm{T} 1, \mathrm{~T} 2, \mathrm{~T} 3$, and $\mathrm{T} 4$ representing a tumor that invades up to the submucosa (T1), the muscularis propia (T2), the subserosa or mesentery (T3), and that perforates the visceral peritoneum or invades neighboring structures (T4), respectively. The definition of node disease was revised as well, with N1 disease including up to two positive nodes and N2 more than two. Stage I includes T1 and T2 tumors without positive nodes or metastatic disease, stage II involves T3 and T4 tumors without nodes or metastases. Positive nodes are defined as stage III, with stage IV being reserved for patients with metastatic disease. ${ }^{15}$ Most reported cases are diagnosed at advanced stages, with up to $40 \%$ of patients presenting with positive nodes and 35 to $50 \%$ of patients presenting with metastatic disease., ${ }^{1,9}$

Only $31.9 \%$ of small intestine tumors are detected in localized stages of invasion. Survival rates are generally lower for jejunal disease when compared to its duodenal counterpart due to its location aiding in the delay of diagnosis in some of the reported series, while others argue that a jejunal location actually adds to a more favorable prognosis. ${ }^{16,17}$ Five-year survival for adenocarcinomas is dependent on disease stage at diagnosis; no specific values are currently available for jejunal adenocarcinoma as a single entity, but small intestine adenocarcinomas are associated with a $85.2 \% 5$-year relative survival for localized disease, $76.2 \%$ for regional disease, $42.2 \%$ for distant disease, and $51.5 \%$ for patients with an undefined stage. $^{16}$

Recurrence is high, presenting in between 40 and $60 \%$ of cases, even after surgery with complete resection. The relapse pattern observed for this type of adenocarcinomas seems to be predominantly systemic. Poor prognostic factors described by Ahmed et al. include the male gender, age $>55$ years old, black race, higher stage at diagnosis, intestinal locations other than the jejunum, poorly differentiated tumors or positive margins after resection. ${ }^{13}$ Positive prognostic factors include an earlier age at diagnosis, lymphadenectomy with $>12$ local nodes, and perhaps even marriage. It is worth mentioning that the study by Xie et al. did not find significant differences in prognosis regarding gender, race, or intestinal location of the tumor. ${ }^{6}$

Coronavirus disease 2019 is an infectious disease caused by the severe acute respiratory syndrome coronavirus 2 , which has managed to become a global health issue, with an estimated $12,964,809$ cases and 570,288 deaths reported to the WHO by mid-July. ${ }^{4}$ While initially thought to only affect the airways, symptoms of organic affection became apparent as the number of cases increased. This phenomenon may be explained by the fact that SARS-CoV-2 binds to its target cells through angiotensin-converting enzyme 2 receptors, which are expressed by epithelial cells in the lungs, the gastrointestinal tract and blood vessels. ${ }^{18}$ Gastrointestinal symptoms may be the first manifestations of COVID-19, preceding any respiratory affection; their frequency varies amongst recent studies, from 3.0 to $39.6 \%$ of cases. ${ }^{19}$ The most common manifestation is diarrhea, which appeared as the initial symptom of illness in up to $19.4 \%$ of patients. ${ }^{18}$ Controversy remains regarding whether gastrointestinal manifestations may impact prognosis for the better or the worse, and more studies need to be carried out. Nonetheless, gastrointestinal manifestations have led to an increase in COVID-19 diagnosis in previously unsuspected patients, since the virus may be found in stool samples long after it stops being present in the pharynx. Pathological examination of the stomach and bowels of COVID-19 patients have demonstrated different degrees of degeneration, necrosis, and detachment of the mucosal epithelium. 5,18,19

The mortality amongst postsurgical patients who are found to be COVID-19-positive ranges from 19.5 to $38.5 \%$ of cases, with complications being 13 times more likely 
amongst these patients. The most commonly referred complications include pulmonary (pneumonia and acute respiratory failure, $p<0.001$ ), hemorrhagic (need for blood transfusion, $p=0.79$ ), and thrombotic manifestations (peripheral and arterial thrombosis, $p=0.004) .^{20}$

\section{Conclusions}

Jejunal adenocarcinoma is a rare form of small intestine malignancy, and the definition of an appropriate management is obstructed by its rarity. Intestinal perforation as the initial manifestation of a jejunal adenocarcinoma is even more infrequent, and in the case presently described it may be linked to the patient being affected by the all-new COVID-19. The relationship between cancer and COVID-19 is still being studied, as well as the postsurgical evolution of COVID-19 patients and its possible causality of intestinal perforation. More studies on the matter of how COVID-19, surgery, and cancer interact with each other need to be conducted. As for jejunal adenocarcinomas, adequate patient follow-up is an important factor towards establishing management guidelines for this particular pathology, with periodic check-ups and imaging studies contributing to establish both the safest surgical approach, as well as the possibility of a role for adjuvant therapy.

\section{Conflict of Interests}

The authors have no conflict of interests to declare.

\section{References}

1 Li J, Wang Z, Liu N, Hao J, Xu X. Small bowel adenocarcinoma of the jejunum: a case report and literature review. World J Surg Oncol 2016;14(01):177-182. Doi: 10.1186/s12957-016-0932-3

2 Siegel RL, Miller KD, Jemal A. Cancer statistics, 2020. CA Cancer J Clin 2020;70(01):7-30. Doi: 10.3322/caac.21590

3 Rongviriyapanich A. Adenocarcinoma of jejunum. J Surg Case Rep 2018;2018(08):rjy234. Doi: 10.1093/jscr/rjy234

4 World Health Organization. 2020WHO Coronavirus Disease (COVID-19) Dashboard. [online] Covid19.who.int.. Available at: <https://covid19.who.int/> [Accessed 14 July 2020]

5 Gupta A, Madhavan MV, Sehgal K, et al. Extrapulmonary manifestations of COVID-19. Nat Med 2020;26(07):1017-1032. Doi: 10.1038/s41591-020-0968-3
6 Xie X, Zhou Z, Song Y, Dang C, Zhang H. Surgical Management and Prognostic Prediction of Adenocarcinoma of Jejunum and Ileum. Sci Rep 2017;7(01):15163. Doi: 10.1038/s41598-017-15633-w

7 McLaughlin PD, Maher MM. Primary malignant diseases of the small intestine. AJR Am J Roentgenol 2013;201(01):W9-14. Doi: 10.2214/ AJR.12.8492

8 Reynolds I, Healy P, Mcnamara DA. Malignant tumours of the small intestine. Surgeon 2014;12(05):263-270. Doi: 10.1016/j. surge.2014.02.003

9 Negoi I, Paun S, Hostiuc S, et al. Most small bowel cancers are revealed by a complication. Einstein (Sao Paulo) 2015;13(04): 500-505. Doi: 10.1590/s1679-45082015ao3380

10 Cimpeanu E, Zafar W, Circiumaru I, Prozumenshikov A, Salman S. Rare presentation of small bowel adenocarcinoma with neuroendocrine differentiation in the jejunum: A case report and summary of diagnostic and management options. Mol Clin Oncol 2019;11(05):461-464. Doi: 10.3892/mco.2019.1925

11 Barsouk A, Rawla P, Barsouk A, Thandra KC. Epidemiology of Cancers of the Small Intestine: Trends, Risk Factors, and Prevention. Med Sci (Basel) 2019;7(03):46. Doi: 10.3390/medsci7030046

12 Young JI, Mongoue-Tchokote S, Wieghard N, et al. Treatment and Survival of Small-bowel Adenocarcinoma in the United States: A Comparison With Colon Cancer. Dis Colon Rectum 2016;59(04): 306-315. Doi: 10.1097/dcr.0000000000000562

13 Ahmed N, Rana HN. Primary Jejunal adenocarcinoma - An unsuspected culprit. J Pak Med Assoc 2018;68(03):471-474

14 Puccini A, Battaglin F, Lenz HJ. Management of Advanced Small Bowel Cancer. Curr Treat Options Oncol 2018;19(12):69. Doi: 10.1007/s11864-018-0592-3

15 Coit DG, Kelsen D, Tang LH, et al. AJCC Cancer Staging Manual. 8th ed. Chicago: Amin MB; 2017:221

16 SEER. 2020Cancer Of The Small Intestine - Cancer Stat Facts. [online] Available at: <https://seer.cancer.gov/statfacts/html/smint.html> [Accessed 16 July 2020]

17 Overman MJ, Hu CY, Kopetz S, Abbruzzese JL, Wolff RA, Chang GJ. A population-based comparison of adenocarcinoma of the large and small intestine: insights into a rare disease. Ann Surg Oncol 2012;19(05):1439-1445. Doi: 10.1245/s10434-011-2173-6

18 Tang L, Cheng X, Tian C, et al. Computed tomography (CT) intestinal alterations of Coronavirus Disease 2019 (COVID-19) from the imaging perspective: a case description. Quant Imaging Med Surg 2020;10(05):1145-1149. Doi: 10.21037/ qims.2020.04.09

19 Schmulson M, Dávalos MF, Berumen J. Beware: Gastrointestinal symptoms can be a manifestation of COVID-19. Rev Gastroenterol Mex 2020;85(03):282-287. Doi: 10.1016/j.rgmx.2020.04.001

20 Doglietto F, Vezzoli M, Gheza F, et al. Factors Associated With Surgical Mortality and Complications Among Patients With and Without Coronavirus Disease 2019 (COVID-19) in Italy. JAMA Surg 2020;••,. Doi: 10.1001/jamasurg.2020.2713 